\title{
Aortic Stenosis Severity is not a Risk Factor for Poststenotic Dilatation of the Ascending Aorta
}

\author{
Kateřina Linhartová, MD; Václav Beránek, MD; František Šefrna, RND*; \\ Iveta Hanišová, MD; Gabriela Štěrbáková, MD; Markéta Pešková, MD
}

\begin{abstract}
Background Dilatation of the ascending aorta in aortic stenosis may be partly explained by intrinsic wall structure changes, but the relative contribution of altered hemodynamics is unclear. The aim of this study was to assess the association between ascending aortic dimensions and valve stenosis severity.

Methods and Results An analysis of echocardiographic examinations was conducted in 296 patients with aortic stenosis (179 males, mean age 71 years), 57 with bicuspid and 239 with tricuspid aortic valve, mean transaortic gradient $43 \pm 20 \mathrm{mmHg}$, and not more than moderate aortic regurgitation. Aortic dimensions at the level of annulus, sinuses of Valsalva, sinotubular junction and proximal ascending aorta were measured. Only height $(\mathrm{p}<0.001)$, degree of aortic regurgitation $(\mathrm{p}<0.01)$ and presence of bicuspid aortic valve $(\mathrm{p}<0.001)$ were independent predictors of ascending aortic dimensions.

Conclusions An independent association between aortic pressure gradients and proximal ascending aortic dimensions was not observed in patients with bicuspid or tricuspid aortic valve stenosis. Therefore, the poststenotic dilatation of the ascending aorta is not explained by aortic stenosis severity itself. Possible nonhemodynamic causes deserve detailed study at the time of diagnosis. (Circ J 2007; 71: 84-88)
\end{abstract}

Key Words: Aortic stenosis; Ascending aorta; Echocardiography

$\mathbf{P}$ oststenotic dilatation of the ascending aorta may accompany aortic stenosis, requiring treatment decision making at the time of valve surgery, ${ }^{1,2}$ Intrinsic aortic wall structure abnormalities, and the effect of altered hemodynamics, are hypothesized to be the main risk factors for aortic dilatation.

Wider aortic root dimensions have been found in patients with a functionally normal bicuspid aortic valve (BAV) than with tricuspid aortic valve (TAV), and irrespective of stenosis or regurgitation severity:,4 Reduced fibrillin-1 content and increased matrix-metalloproteinase production, contributing to derangement of wall structure and aortic dilatation, have been identified in the vasculature of patients with BAV5-7

With regard to hemodynamics, a positive association between the degree of aortic regurgitation and proximal ascending aortic dimensions has been found in patients with BAV and TAV3,8 However, the effect of the high velocity stenotic jet on the aortic dimensions is unclear. In patients without valvular dysfunction, Nkomo et al found a wider ascending aorta and higher transaortic flow velocity in patients with BAV than with TAV4. In patients with BAV stenosis, no or even inverse association between ascending aortic dimensions and severity of stenosis was found, ${ }^{8} 9$ In

(Received May 29, 2006; revised manuscript received September 26, 2006; accepted October 5, 2006)

First Department of Medicine, *Department of Health Statistics, Charles University of Prague, School of Medicine Hospital, Pilsen, Czech Republic

Oral presentation at the Congress of the European Society of Cardiology in Stockholm, September 4th, 2005.

Mailing address: Kateřina Linhartová, MD, Department of Cardiology, Cardiovascular Center, Charles University School of Medicine Hospital Motol, Prague, V Úvalu 84, 15006 Prague, Czech Republic.

E-mail: linhartkaterina@atlas.cz patients with TAV, this issue has not yet been specifically addressed.

Therefore, the aim of our study was to assess the relationship between ascending aortic dimensions and aortic jet velocity in patients with dominant aortic stenosis and identifiable TAV or BAV morphology.

\section{Methods}

We performed a retrospective analysis of prospectively collected data from the Department of Medicine, Charles University of Prague, School of Medicine Hospital in Pilsen, where 15,789 echocardiographic examinations were performed between January 2002 to June 2004. From this database we identified 598 patients with dominant aortic stenosis with peak velocity $\geq 2.5 \mathrm{~m} / \mathrm{s}$. Cases with more than moderate aortic regurgitation, Marfan syndrome, aortic dissection, congenital heart disease except for BAV, infective endocarditis, severe left ventricular dysfunction (ejection fraction $<30 \%$ ), unstable hemodynamics (systolic blood pressure $<100 \mathrm{mmHg}$ ) were not included. A total of 323 patients were initially selected. Excluding patients with an incomplete study or with unidentifiable valve morphology, 296 patients were enrolled for the final data analysis. We performed a standard transthoracic echocardiographic examination of all patients, and transesophageal echocardiography (TEE) of 118 (40\%) of them (GE Vingmed System Five or Vivid Five, Horten, Norway, TU4 multiplane TEE probe). Blood pressure and anthropometric data were obtained at the time of the examination. The study followed the principles established in the Declaration of Helsinki.

\section{Echocardiographic Analysis}

Videotapes of all examinations were analyzed. All dimensions were measured offline by one echocardiographer. 
Table 1 Baseline Characteristics of 296 Patients With Dominant Aortic Stenosis and Comparison Between Patients With Bicuspid and Tricuspid Aortic Valve Stenosis

\begin{tabular}{|c|c|c|c|c|}
\hline & $\begin{array}{c}A l l \\
(n=296)\end{array}$ & $\begin{array}{c}B A V \\
(n=57)\end{array}$ & $\begin{array}{c}T A V \\
(n=239)\end{array}$ & $p$ value* \\
\hline Gender, males (\%) & $179(60)$ & $39(68)$ & $140(59)$ & $N S$ \\
\hline Age (years) & $71(62,76)$ & $62(52,69)$ & $71(66,76)$ & $<0.001$ \\
\hline Height $(\mathrm{cm})$ & $170(162,175)$ & $170(164,175)$ & $170(162,175)$ & $N S$ \\
\hline Weight (kg) & $80(70,91)$ & $83(70,91)$ & $80(70,92)$ & $N S$ \\
\hline Body surface area $\left(\mathrm{m}^{2}\right)$ & $1.9(1.8,2.1)$ & $1.9(1.8,2.0)$ & $1.9(1.8,2.0)$ & $N S$ \\
\hline Body mass index $\left(\mathrm{kg} / \mathrm{m}^{2}\right)$ & $28(25,31)$ & $29(24,32)$ & $28(25,31)$ & $N S$ \\
\hline Systolic blood pressure ( $\mathrm{mmHg}$ ) & $140(120,150)$ & $140(125,150)$ & $140(120,150)$ & $N S$ \\
\hline Diastolic blood pressure ( $\mathrm{mmHg}$ ) & $80(70,90)$ & $80(80,90)$ & $80(70,85)$ & $N S$ \\
\hline Maximal aortic valve gradient $(\mathrm{mmHg})$ & $65(40,87)$ & $79(60,92)$ & $63(39,86)$ & $<0.01$ \\
\hline Mean aortic valve gradient $(\mathrm{mmHg})$ & $42(25,56)$ & $50(36,61)$ & $40(25,55)$ & $N S$ \\
\hline \multicolumn{5}{|l|}{ Aortic regurgitation severity } \\
\hline No regurgitation $n(\%)$ & $99(34)$ & $18(31)$ & $81(34)$ & $N S$ \\
\hline $1+/ 4 n(\%)$ & $163(55)$ & $34(60)$ & $128(54)$ & NS \\
\hline $2+14 n(\%)$ & $34(11)$ & $5(9)$ & $30(12)$ & $N S$ \\
\hline
\end{tabular}

Values are presented as median (25th, 75 th percentile).

Data on gender and aortic regurgitation severity are presented as numbers and percentages.

*Bicuspid vs tricuspid aortic valve patients, Mann-Whitney U-test.

$B A V$, bicuspid aortic valve; TAV, tricuspid aortic valve.

Data from 3 beats were measured and averaged. The aorta was measured from the 2-dimensional (D) parasternal long-axis view by the leading edge-to-leading edge method according to standard criteria, ${ }^{10}$ at the level of the aortic annulus, sinuses of Valsalva, sinotubular junction and proximal ascending aorta, $1-1.5 \mathrm{~cm}$ from the sinotubular junction. The ejection fraction was assessed from the $\mathrm{M}$ mode, using the Teichholz formula or from the 2-D 4 chamber view using the Simpson's formula.

BAV was defined by the presence of 2 commissures and 2 aortic cusps ${ }^{11}$ on the parasternal or mid-esophageal shortaxis view. BAV was assessed by 2 echocardiographers from our team, whose consensus regarding valve morphology was reached in all patients included in the present study. At the time of examination, peak and mean aortic velocities were measured by continuous wave Doppler, and the gradients counted using the modified Bernoulli equation; the aortic valve area was measured by the continuity equation! ${ }^{2}$ The degree of regurgitation was assessed semi-quantitatively from the regurgitation jet area and width, according to the American Society of Echocardiography guidelines, ${ }^{13}$ converting the terms none, mild, and moderate into numbers 0,1 and 2 .

\section{Statistical Analysis}

Continuous measurements are presented as median and interquartile range, as some of the variables (proximal ascending aortic dimensions and aortic valve gradients) were not normally distributed. Categorical measurements are presented as numbers and percentages. First, continuous and categorical variables were compared between patients with BAV and TAV, using the Mann-Whitney U-test and the Kruskal-Wallis test. A Box-Cox transformation of aortic dimensions was performed to achieve normal distribution. The correlation between aortic dimensions and the hemodynamic and anthropometric parameters was then studied. We performed separate sets of calculations at each of the 4 aortic levels. Aortic dimensions, first unadjusted, and then indexed by height, were used as dependent variables. Age, anthropometric parameters (height, weight, body surface area (BSA)), and valve disease severity parameters (maximal and mean gradients, severity of regurgitation) were independent variables. Spearman rank correlation coefficients were counted in the univariate analysis. Further, independent predictors of aortic dimensions were evaluated by linear step-wise regression. A p-value $<0.05$ was considered statistically significant.

\section{Results}

Baseline characteristics of the 296 patients included in the study and comparisons between patients with BAV and TAV are shown in Table 1. The distribution of transaortic velocities in the whole study group is shown in Fig 1. Severe aortic stenosis with mean aortic gradient $>50 \mathrm{mmHg}$ was present in $34 \%$ of patients, and peak aortic gradient $>50 \mathrm{mmHg}$ in $66 \%$ of patients. The stenosis was pure in one-third of the study group, and accompanied by mild regurgitation in $56 \%$. Moderate regurgitation was present in $11 \%$ of patients, all of whom had severe stenosis with orifice area $<1 \mathrm{~cm}^{2}$. The patients with BAV were 9 years younger, on average, than those with TAV and had higher transaortic jet velocity, but did not differ in the severity of regurgitation.

Using univariate analysis for the whole study group, we found a positive association of aortic dimensions with severity of regurgitation $(\mathrm{p}<0.01)$ (Fig 2), and a weak but significant association with severity of stenosis $(\mathrm{p}<0.05)$ (Fig 3). The correlations between aortic dimensions at each of the 4 measured levels and the anthropometric and valve disease parameters are listed in Table 2 .

The ascending aorta at all 4 measured levels was significantly wider in patients with BAV than with TAV (Table 3 ).

Significant univariate correlates were entered into the multivariate model and the results are shown in Table 4. The aortic diameters had an independent positive association with the degree of aortic regurgitation $(\mathrm{p}<0.01)$ and the presence of BAV $(\mathrm{p}<0.001)$. Of the anthropometric parameters, only height had an independent correlation with the aortic diameters $(p<0.001)$ at all 4 levels, therefore we considered indexing the aortic dimensions by height appropriate for our study group.

Presence of BAV and severity of regurgitation remained the only positive independent predictors of aortic dimen- 


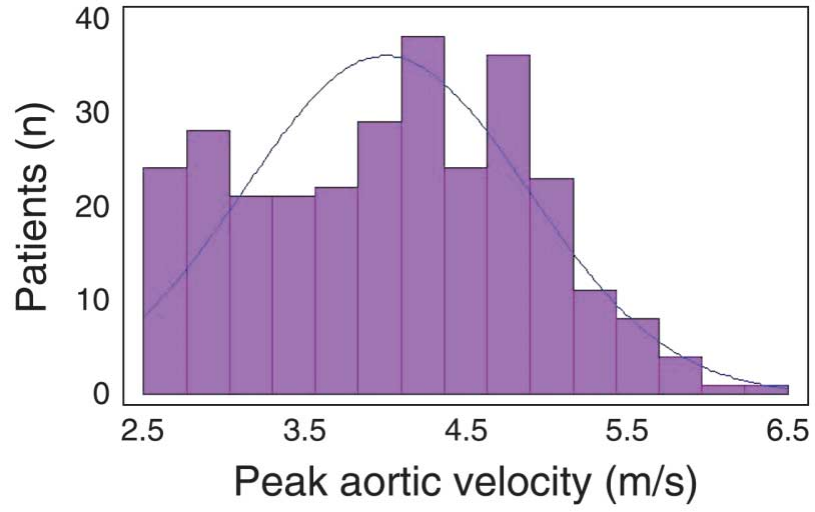

Fig 1. Distribution of peak aortic velocities in the 296 patients with dominant aortic stenosis.

sions indexed by height at the same levels of significance (data not shown).

\section{Discussion}

We did not observe an independent association between transaortic pressure gradients and any diameter of the aortic root and proximal ascending aorta, despite evaluating a large group of patients with a wide range of stenosis severi-

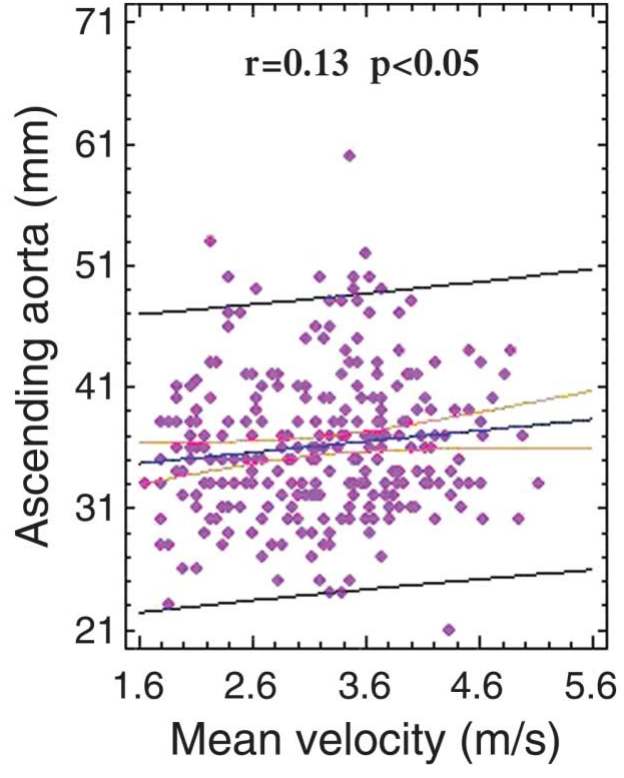

Fig 3. Association of mean transaortic jet velocity with the dimension of proximal ascending aorta. The association with the dimensions of the annulus, Valsalva sinuses and sinotubular junction was not significant. r, Spearman rank correlation coefficient; $p, p$ value.

\section{Valsalva sinus}

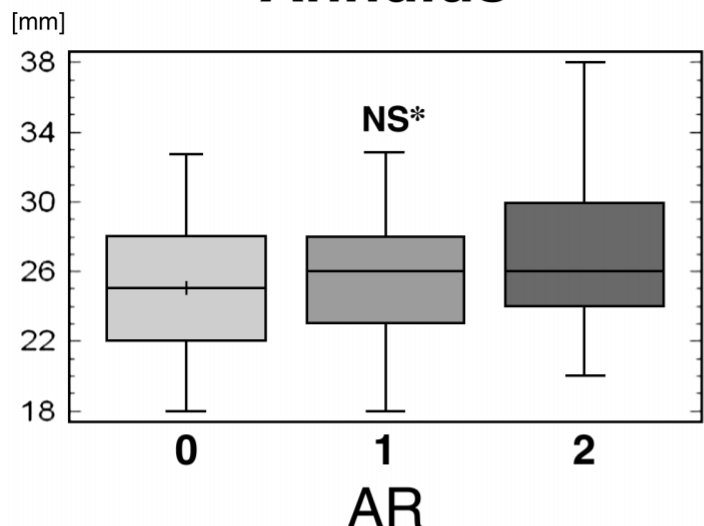

Sinotubular junction

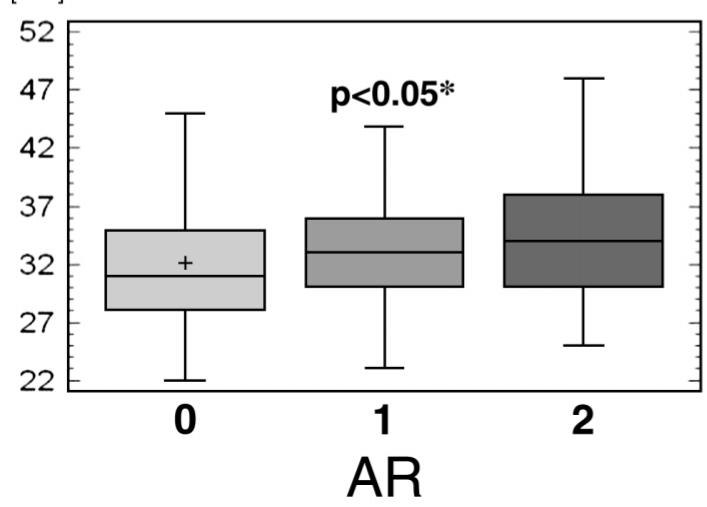

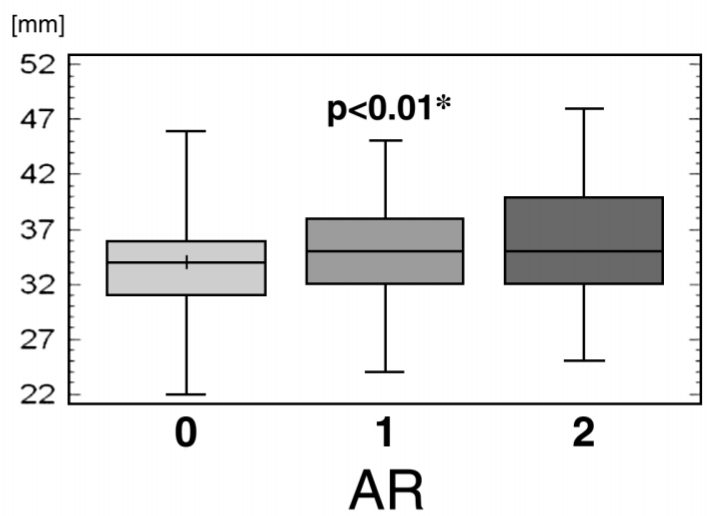

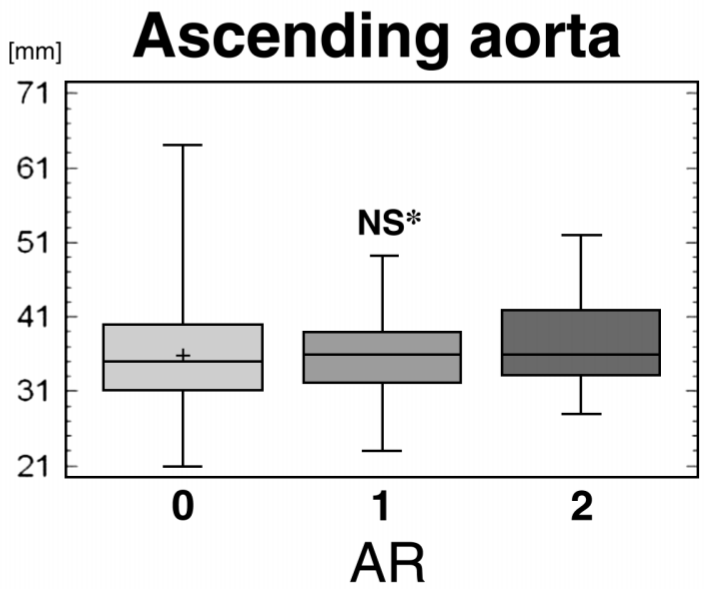

Fig 2. Association between aortic dimensions from the annulus to the proximal ascending aorta and severity of aortic regurgitation (AR). *Spearman rank correlation. 
Table 2 Correlation of Aortic Dimensions With Anthropometric and Aortic Valve Disease Parameters (Univariate Analysis*)

\begin{tabular}{|c|c|c|c|c|c|c|c|c|}
\hline & \multicolumn{2}{|c|}{ Annulus } & \multicolumn{2}{|c|}{$\begin{array}{l}\text { Valsalva } \\
\text { sinuses }\end{array}$} & \multicolumn{2}{|c|}{$\begin{array}{l}\text { Sinotubular } \\
\text { junction }\end{array}$} & \multicolumn{2}{|c|}{$\begin{array}{c}\text { Proximal } \\
\text { ascending aorta }\end{array}$} \\
\hline & $r$ & $p$ value & $r$ & $p$ value & $r$ & $p$ value & $r$ & $p$ value \\
\hline Height & 0.39 & $<0.001$ & 0.40 & $<0.001$ & 0.33 & $<0.001$ & 0.25 & $<0.001$ \\
\hline Weight & 0.28 & $<0.001$ & 0.15 & $<0.01$ & 0.14 & $<0.05$ & 0.14 & $<0.05$ \\
\hline Body surface area & 0.35 & $<0.001$ & 0.23 & $<0.001$ & 0.20 & $<0.01$ & 0.18 & $<0.01$ \\
\hline Age & -0.19 & $<0.01$ & -0.13 & $<0.05$ & -0.09 & $N S$ & -0.17 & $<0.01$ \\
\hline Maximal aortic valve gradient & 0.01 & $N S$ & 0.09 & NS & 0.02 & $N S$ & 0.15 & $<0.05$ \\
\hline Mean aortic valve gradient & 0.06 & $N S$ & 0.10 & $N S$ & 0.00 & $N S$ & 0.13 & $<0.05$ \\
\hline Maximal aortic jet velocity & 0.01 & $N S$ & 0.09 & $N S$ & 0.02 & $N S$ & 0.15 & $<0.05$ \\
\hline Mean aortic jet velocity & 0.06 & $N S$ & 0.10 & $N S$ & 0.00 & $N S$ & 0.13 & $<0.05$ \\
\hline Aortic regurgitation severity & 0.08 & NS & 0.17 & $<0.01$ & 0.15 & $<0.05$ & 0.1 & NS \\
\hline
\end{tabular}

*r values are Spearman rank correlation coefficients.

Table 3 Comparison of Ascending Aortic Dimensions in Patients With Bicuspid vs Tricuspid Aortic Valve Stenosis

\begin{tabular}{lcccc}
\hline \hline & $\begin{array}{c}\text { All } \\
(n=296)\end{array}$ & $\begin{array}{c}\text { BAV } \\
(n=57)\end{array}$ & $\begin{array}{c}\text { TAV } \\
(n=239)\end{array}$ & $p$ value* \\
\hline Aortic annulus $(\mathrm{cm})$ & $2.6(2.3,2.8)$ & $2.7(2.4,3.0)$ & $2.5(2.3,2.8)$ & $<0.01$ \\
Valsalva sinuses $(\mathrm{cm})$ & $3.5(3.2,3.8)$ & $3.8(3.4,4.1)$ & $3.4(3.2,3.7)$ & $<0.001$ \\
Sinotubular junction $(\mathrm{cm})$ & $3.2(2.9,3.6)$ & $3.5(3.2,3.9)$ & $3.2(2.9,3.5)$ & $<0.001$ \\
Proximal ascending aorta $(\mathrm{cm})$ & $3.6(32,40)$ & $4.0(3.5,4.3)$ & $3.5(3.1,3.8)$ & $<0.001$ \\
\hline
\end{tabular}

Values are presented as median (25th, 75 th percentile).

Abbreviations see in Table 1.

*Bicuspid vs tricuspid aortic valve patients, Mann-Whitney U-test.

Table 4 Correlation of Aortic Dimensions With Anthropometric and Aortic Valve Disease Parameters (Multivariate Analysis*)

\begin{tabular}{|c|c|c|c|c|c|c|c|}
\hline \multirow[b]{2}{*}{ Aortic dimensions } & \multirow{2}{*}{$\begin{array}{l}\text { Value }(\mathrm{cm}) \\
\text { Mean } \pm S D\end{array}$} & \multicolumn{2}{|c|}{ Height } & \multicolumn{2}{|c|}{$B A V$} & \multicolumn{2}{|c|}{ Aortic regurgitation } \\
\hline & & $\begin{array}{c}\text { Partial } \\
\text { correlation }\end{array}$ & $p$ value & $\begin{array}{c}\text { Partial } \\
\text { correlation }\end{array}$ & $p$ value & $\begin{array}{c}\text { Partial } \\
\text { correlation }\end{array}$ & $p$ value \\
\hline Annulus & $2.6 \pm 0.4$ & 0.40 & $<0.001$ & 0.23 & $<0.001$ & & $N S$ \\
\hline Valsalva sinuses & $3.3 \pm 0.5$ & 0.36 & $<0.001$ & 0.34 & $<0.001$ & 0.22 & $<0.01$ \\
\hline Sinotubular junction & $3.5 \pm 0.5$ & 0.34 & $<0.001$ & 0.30 & $<0.001$ & 0.16 & $<0.05$ \\
\hline Proximal ascending aorta & $3.6 \pm 0.7$ & 0.26 & $<0.001$ & 0.411 & $<0.001$ & & NS \\
\hline
\end{tabular}

*Partial correlation coefficients using linear step-wise regression. Abbbreviation see in Table 1.

ty. To our knowledge this is the first echocardiographic study addressing this association in patients mainly with stenosis of the TAV. We identified severity of aortic regurgitation and number of aortic valve cusps as independent predictors of aortic dimensions indexed by height.

We believe that our data are important for the following reasons. First, we studied the hemodynamic concept of a relationship between the high velocity jet in aortic stenosis and aortic dimensions, and second, we extended our attention beyond the aortic root to the proximal ascending aortic diameter. The new finding of a positive correlation of this dimension with the aortic gradient from the univariate analysis was not significant in the multivariate model, with valve morphology as an independent variable. Thus, it may be explained by the presence of more severe stenosis in the patients with BAV in our study group.

The velocity, however, is one important aspect of the stenotic jet, while other fluid dynamic factors (eg, the shape of the jet) may influence the aortic dimensions. The shape of the stenotic orifice may affect the spatial orientation of the aortic jet and the distribution of the induced vortices. Thus, the irregular orifice in BAV may result in a more eccentric jet contributing to remodelling of the proximal aorta. As shown by Robicsek et al, the degree of turbulence may not be proportional to the degree of stenosis! 14 The influence of flow distribution deserves detailed attention also in TAV stenosis with its complex stellate orifice, which was beyond the scope of our clinical study.

The independent positive association between regurgitation severity and aortic dimensions suggests the importance of the hemodynamic burden of higher stroke volume for the aortic dimensions. In BAV, manifestation of intrinsic wall pathology ${ }^{5-7}$ may be initiated or aggravated by altered hemodynamics. Our data suggest that in TAV stenosis if it is accompanied by aortic dilatation the possibility of significant aortic wall tissue abnormalities should also, be investigated.

As specifically height and not BSA were entered in the multivariate analysis in our obese population, we considered indexing by height more appropriate than by BSA; however, the indexing did not change the outcome of our study. 


\section{Study Limitations}

These originate mainly from retrospective study group selection in a tertiary care centre with cardiac surgery First, the assessment of valve morphology was based more often on a transthoracic examination, which is less accurate than TEE; ${ }^{15}$ however, such inaccuracy would not alter the relationship between dimensions and hemodynamics. Second, selection was biased towards patients with more severe valve disease, including those evaluated for valve surgery, in whom the heavily calcified valves may be less amenable to reliable morphology assessment. Significant correlation of aortic dimensions with aortic regurgitation, although graded as mostly mild in our study, may also reflect limitations in regurgitation evaluation. Finally, this was a crosssectional study and the impact of valve disease progression rate on aortic dimensions is of further interest.

\section{Conclusion}

We did not observe any independent association between aortic jet velocity and the dimensions of the ascending aorta in patients with aortic stenosis. We confirmed a positive independent association between aortic dimensions and the presence of BAV, height and regurgitation severity. Therefore, post stenotic dilatation of the ascending aorta is not explained by the stenosis itself in patients with BAV, but also with TAV stenosis. It may be a marker of intrinsic aortic wall structure pathology and thus deserves detailed study at the time of diagnosis.

\section{Acknowledgments}

This study was supported by a grant from the Internal Grant Agency, Ministry of Health NR/8306-5, Prague, Czech Republic and by the cardiovascular research project of Charles University, Prague, Czech Republic, nr. MSM0021620817, entitled 'The invasive approach to myocardial salvage and regeneration'.

\section{References}

1. Crawford MH, Roldan CA. Prevalence of aortic root dilatation and small aortic roots in valvular aortic stenosis. Am J Cardiol 2001; 87: $1311-1313$.

2. Matsuyama K, Usui A, Akita T, Yoshikawa M, Murayama M, Yano $\mathrm{T}$, et al. Natural history of a dilated ascending aorta after aortic valve replacement. Circ J 2005; 69: 392-396.

3. Keane MG, Wiegers SE, Plappert T, Pochettino A, Bavaria JE, St John Sutton MG. Bicuspid aortic valves are associated with aortic dilatation out of proportion to coexistent valvular lesions. Circulation 2000; 102(Suppl III): III-35-III-39.

4. Nkomo VT, Enriquez-Sarano M, Ammash NM, Melton J III, Bailey KR, Desjardins V, et al. Bicuspid aortic valve associated with aortic dilatation: A community-based study. Arterioscler Thromb Vasc Biol 2003; 23: 351-356.

5. Bondermann D, Gharenbaghi-Schnell E, Wollenek G, Maurer G, Baumgartner H, Lang IM. Mechanisms underlying aortic dilatation in congenital aortic valve malformation. Circulation 1999; 99: $2138-$ 2143.

6. Fedak PWM, de Sa MPL, Verma S, Nili N, Kazemian P, Butany J, et al. Vascular matrix remodeling in patients with bicuspid aortic valve malformations: Implications for aortic dilatation. J Thorac Cardiovasc Surg 2003; 126: 797-805.

7. Boyum J, Fellinger EK, Schmoker JD, Trombley L, McPartland K, Ittleman FP, et al. Matrix metalloproteinase activity in thoracic aortic aneurysmas associated with bicuspid and tricuspid aortic valves. $J$ Thorac Cardiovasc Surg 2004; 127: 686-691.

8. Novaro GM, Tiong IY, Pearce GL, Grimm RA, Smedira N, Griffin BP. Features and predictors of ascending aortic dilatation in association with a congenital bicuspid aortic valve. Am J Cardiol 2003; 92: 99-101.

9. Yasuda H, Nakatani S, Stugaard M, Tsujita-Kuroda Y, Bando K, Kobayashi J, et al. Failure to prevent progressive dilatation of ascending aorta by aortic valve replacement in patients with bicuspid aortic valve: Comparison with tricuspid aortic valve. Circulation 2003; 108(Suppl II): II-291-II-294.

10. Roman MJ, Devereux RB, Kramer-Fox R, O'Loughlin J. Twodimensional echocardiographic aortic root dimensions in normal children and adults. Am J Cardiol 1989; 64: 507-512.

11. Brandenburg RO Jr, Tajik AJ, Edwards WD, Reeder GS, Shub C, Seward JB. Accuracy of 2-dimensional echocardiographic diagnosis of congenitally bicuspid aortic valve: Echocardiographic-anatomic correlation in 115 patients. Am J Cardiol 1983; 51: 1469-1473.

12. Quinones MA, Otto CM, Stoddard M, Waggoner A, Zoghbi WA. Recommendations for quantification of Doppler echocardiography: A report from the Doppler quantification task force of the nomenclature and standards committee of the American Society of Echocardiography. J Am Soc Echocardiogr 2002; 15: 167-184.

13. Zoghbi WA, Enriquez-Sarano M, Foster E, Grayburn PA, Kraft CD, Levine RA, et al. Recommendations for evaluation of the severity of native valvular regurgitation with two-dimensional and Doppler echocardiography. J Am Soc Echocardiogr 2003; 16: 777-802.

14. Robicsek F, Thubrikar MJ, Cook WJ, Fowler B. The congenitally bicuspid aortic valve: How does it function? Why does it fail? Ann Thorac Surg 2004; 77: 177-185.

15. Chan KL, Stinson WA, Veinot JP. Reliability of transthoracic echocardiography in the assessment of aortic valve morphology: Pathological correlation in 178 patients. Can J Cardiol 1999; 1: 48-52. 